\title{
MORFOLOGI VEGETATIF JENIS POHON TENGKAWANG (Shorea spp) DI DESA MENSIAU KECAMATAN BATANG LUPAR KABUPATEN KAPUAS HULU
}

(The Vegetative Morphology of Tengkawang Tree (Shorea spp) in Mensiau Village, Batang Lupar Subdistrict, Kapuas Hulu Regency)

\author{
Riska dan Togar Fernando Manurung \\ Fakultas Kehutanan Universitas Tanjungpura Jalan Imam Bonjol Pontianak 78124 \\ Email : riska.arents@gmail.com
}

\begin{abstract}
Tengkawang is a Shorea tree which includes in Dipterocarpacea family. This tree was the indigenous species of West Kalimantan, and mostly found in Kapuas Hulu Regency. Tengkawang seed which is the mascot of West Kalimantan Province was used to produce vegetable oil, chocolate, medicine, margarine, candles, and cosmetics. One of the villages which famous on Tengkawang products were Mensiau village which located in Batang Lupar sub district, Kapuas Hulu Regency. The objective of research was to inventory the diversity of Tengkawang tree in Mensiau village, Batang Lupar sub district, Kapuas Hulu Regency, and identification and made a description on morphology of Tengkawang tree. The research was conducted from May until August 2017. The methods used exploration on four lines in the forest of Mensiau village. The research found total individuals of Tengkawang tree was 1,689 trees. There were five types of Tengkawang, namely Shorea stenoptera, Shorea beccariana, Shorea pinanga, Shorea seminis and Shorea macrophylla. The local names of Tengkawang in Mensiau village were Engkabang Tungkul, Engkabang Rambai, Engkabang Trindak, and Engkabang Biasa. The total individuals of Shorea stenoptera was 408 tree, Shorea beccariana was 571 tree, Shorea pinanga was 370 tree, Shorea seminis was 186 tree and Shorea macrophylla was 154 tree. The efforts on conservation of Tengkawang tree in Mensiau village was needed because the forest in the village was suitable for the habitat of Tengkawang.
\end{abstract}

Keywords : Kapuas Hulu, Shorea beccariana, Shorea macrophylla, Shorea pinanga, Shorea seminis, Shorea stenoptera, Tengkawang

\section{PENDAHULUAN}

Tengkawang adalah jenis Shorea yang telah lama dikenal di Indonesia, termasuk dalam famili Dipterocarpacea. Daerah penyebarannya adalah Asia Tenggara yaitu: Thailand, Malaysia, Indonesia (Kalimantan dan Sumatera), Serawak, Sabah dan Phillipina. Tengkawang merupakan salah satu flora yang tumbuh di hutan Kalimantan Barat dan telah dibudidayakan sejak 1881. Tengkawang adalah genus Shorea atau meranti, membuat pohon ini mempunyai nilai ekonomis yang baik, yakni penghasil minyak nabati. Salah satu meranti yang merupakan tanaman endemik Kalimantan Barat adalah meranti merah (Shorea stenoptera), dalam bahasa setempat disebut Tengkawang Tungkul, dalam Bahasa Inggris dikenal dengan illipe nut atau Borneo tallow nut. Minyak perdagangan yang lebih sering digunakan adalah tengkawang oil. 
Pohon penghasil tengkawang umumnya berbunga pada bulan September Oktober dan buah masak pada bulan Januari - Maret, berbuah lebat setelah kemarau panjang (Anonim, 1986).

Keberadaan pohon tengkawang saat ini di hutan alam sudah sangat sedikit. Kondisi ini disebabkan salah satunya oleh pembalakan liar yang semakin marak serta eksploitasi oleh sebagian besar pemegang Ijin Usaha Pemanfaatan Hasil Hutan Kayu (IUPHHK) yang dilakukan tanpa mengindahkan aspek kelestarian pohon tengkawang. Namun demikian, masyarakat sudah mulai paham arti buah tengkawang bagi kehidupan mereka. Masyarakat sudah membudidayakan jenis tengkawang di pekarangan maupun kebun, tetapi pengolahan buah tengkawang masih secara tradisional dalam arti belum memperhitungkan aspek teknologi, sehingga hasilnya belum memuaskan. Umumnya di Kalimantan Barat tengkawang dihasilkan dari spesies $S$. stenoptera dan $S$. pinanga yang tergabung dalam kelompok meranti merah (Jafarsidik dan Oetja, 1982; Appanah, 1998).

Tengkawang yang diusahakan selama ini sebagian besar tumbuh secara alamiah hampir di seluruh wilayah Kalimantan Barat. Salah satunya penghasil biji tengkawang di daerah Kalimantan Barat adalah di Desa Mensiau Kecamatan Batang Lupar Kabupaten Kapuas Hulu. Biji tengkawang yang merupakan maskot daerah Kalimantan Barat sudah sejak ratusan tahun yang lalu dimanfaatkan untuk menghasilkan minyak nabati. Turunannya juga digunakan sebagai bahan dasar pembuatan makanan, coklat, obat, margarin, lilin, dan kosmetik. Sedangkan di Desa Mensiau sendiri buah tengkawang dimanfaatkan untuk minyak goreng, penyedap nasi, dan ampas dari buah tengkawang dimanfaatkan untuk makanan ternak seperti babi dan ikan. Pohon tengkawang tumbuh dan tersebar luas di daerah pedalaman, di pinggiran sungai dan di dataran rendah maupun pegunungan. Penelitian bertujuan untuk melakukan inventarisasi jenis pohon tengkawang dan melakukan identifikasi morfologi vegetatif jenis pohon tengkawang di desa Mensiau Kecamatan Batang Lupar Kabupaten Kapuas Hulu.

\section{METODE PENELITIAN}

Penelitian dilakukan di hutan yang terdapat di Desa Mensiau Kecamatan Batang Lupar Kabupaten Kapuas Hulu. Waktu penelitian pada bulan Mei sampai Agustus 2017. Alat yang digunakan pada penelitian ini yakni Kompas, Parang, Kamera, Buku derteminasi, ATK, GPS, Peta lokasi penelitian, Thally shat, alkoho $170 \%$, kertas koran, gunting stek, kantong plastik, cutter, isolasi dan label, galah, sasak dan gunting. Bahan yang digunakan adalah semua pohon tengkawang yang terdapat di Desa Mensiau Kecamatan Batang Lupar Kabupaten Kapuas Hulu.

Penelitian menggunakan metode jalur eksplorasi berdasarkan Rugayah (2004). Inventarisasi pohon tengkawang dengan cara jelajah, yaitu dengan 
menjelajahi setiap hutan yang mewakili tipe-tipe ekosistem tengkawang. Jalur pengamatan dengan panjang 1 kilometer dan batas kanan - kiri masing-masing 10 meter. Dalam setiap dusun dibuat satu jalur pengamatan. Semua pohon tengkawang yang ditemukan didokumentasi dan dicatat titik koordinatnya. Kemudian diambil daun untuk identifikasi meng gunakan buku determinasi Shorea spp.

Pengumpulan data meliputi data primer dan data sekunder. Data primer adalah data yang diperoleh langsung di lapangan berupa ciri-ciri morfologi vegetatif maupun generatif, nama ilmiah, habitat, keting gian tempat, nomor koleksi, dan tanggal pengamatan. Pencatatan tersebut dilaku kan pada semua jenis pohon tangkawang yang ditemukan di dalam Tabel 1. Jenis Tengkawang yang ditemukan di Desa Mensiau Kecamatan Batang Lupar Kabupaten Kapuas Hulu (Tengkawang tree at Mensiau village, Batang Lupar Subdistrict, Kapuas Hulu regency)

\section{Jalur jelajah 1}

Jalur jelajah satu dilaksanakan dalam kawasan yang tidak jauh dari pemukiman penduduk Desa Mensiau Kecamatan Batang Lupar Kabupaten Kapuas Hulu. Kondisi lahan merupakan hutan tembawang dengan titik koordinat North (Utara 108.923) dan East (Timur kawasan Desa Mensiau Kecamatan Batang Lupar Kabupaten Kapuas Hulu. Data sekunder penelitian adalah nama lokal pohon tengkawang yang ditemui berdasarkan pengetahuan masyarakat setempat dan keadaan umum lokasi penelitian.

\section{HASIL DAN PEMBAHASAN}

Hasil penelitian yang dilakukan pada empat jalur jelajah di Desa Mensiau Kecamatan Batang Lupar Kabupaten Kapuas Hulu ditemukan 5 (lima) jenis tengkawang (Shorea), yaitu jenis Shorea stenoptera Burck, Shorea beccariana Burck, Shorea pinanga Scheff, Shorea seminis (de Vriese) Sloot, dan Shorea macrophylla (de Vriese) P.S. Ashton. Jenis Tengkawang (Shorea spp) yang ditemukan di lokasi penelitian disajikan pada Tabel 1 . 
Tabel 2. Jenis Tengkawang yang ditemukan pada jalur jelajah 1 di Desa Mensiau Kecamatan Batang Lupar Kabupaten Kapuas Hulu (Tengkawang tree at $1^{\text {st }}$ line of inventory at Mensiau village, Batang Lupar Subdistrict, Kapuas Hulu regency)

\begin{tabular}{llllr}
\hline No & Nama ilmiah & Nama dagang & Nama lokal & Jumlah \\
\hline 1. & Shorea stenoptera & Meranti kuning & Engkabang tungkul & 41 \\
2. & Shorea macrophylla & meranti merah & Engkabang biasa & 154 \\
3. & Shorea beccariana & Meranti merah & Engkabang rambai & 40 \\
4. & Shorea seminis & Meranti balau & Engkabang trindak & 86 \\
\hline & & & Total & 321
\end{tabular}

\section{Jalur jelajah 2}

Jalur jelajah 2 dimulai dari tepi kawasan yang tidak jauh berbatasan langsung dengan pemukiman masyarakat. Kondisi lahan merupakan semak belukar dan tengkawang yang ditemukan berada di tepian sungai di Dusun Entebuluh. Titik koordinat jalur 2 adalah $\mathrm{N}$ (Utara. 109.538) dan $\mathrm{E}$
(Timur. 11215,034). Jenis tengkawang yang ditemukan pada jalur jelajah 2 sebanyak 3 jenis dari 5 jenis tengkawang yang ada di Desa Mensiau Kecamatan Batang Lupar Kabupaten Kapuas Hulu. Jenis tengkawang yang ditemukan pada jalur jelajah 2 disajikan pada Tabel 3.

Tabel 3. Jenis Tengkawang yang ditemukan pada jalur jelajah 2 di Desa Mensiau Kecamatan Batang Lupar Kabupaten Kapuas Hulu (Tengkawang tree at $2^{\text {nd }}$ line of inventory at Mensiau village, Batang Lupar Subdistrict, Kapuas Hulu regency)

\begin{tabular}{llllr}
\hline No & Nama ilmiah & Nama dagang & Nama lokal & Jumlah \\
\hline 1. & Shorea stenoptera & Meranti kuning & Engkabang tungkul & 160 \\
2. & Shorea beccariana & Meranti merah & Engkabang rambai & 175 \\
3. & Shorea seminis & Meranti balau & Engkabang trindak & 56 \\
\hline & & & Total & 391
\end{tabular}

\section{Jalur jelajah 3}

Jalur jelajah 3 pada hutan tembawang yang terdapat di tepian kawasan Dusun Kelawik. Kawasan tidak jauh berbatasan langsung dengan pemukiman masyarakat dengan titik koordinat North (Utara, 108.770) dan East (Timur, 11216.575). Jenis tengkawang yang ditemukan pada jalur jelajah 3 sejumlah 3 jenis yaitu Shorea stenoptera, Shorea pinanga dan Shorea seminis. Jenis tengkawang yang ditemukan di jalur jelajah 3 di Desa Mensiau Kecamatan Batang Lupar Kabupaten Kapuas Hulu disajikan pada Tabel 4. 
Tabel 4. Jenis Tengkawang yang ditemukan pada jalur jelajah 3 di Desa Mensiau Kecamatan Batang Lupar Kabupaten Kapuas Hulu (Tengkawang tree at $3^{\text {rd }}$ line of inventory at Mensiau village, Batang Lupar Subdistrict, Kapuas Hulu regency)

\begin{tabular}{llllr}
\hline No & Nama ilmiah & Nama dagang & Nama lokal & Jumlah \\
\hline 1. & Shorea stenoptera & Meranti kuning & Engkabang tungkul & 40 \\
2. & Shorea pinanga & Meranti merah & Engkabang langai & 370 \\
3. & Shorea seminis & Meranti balau & Engkabang trindak & 44 \\
\hline & & & Total & 454 \\
\hline
\end{tabular}

\section{Jalur jelajah 4}

Jalur jelajah 4 dimulai dari batas kawasan Dusun Kelawik (RT Kelawik) dengan habitat semak belukar dan hutan tembawang yang sangat jauh dari permukiman masyarakat. Titik koordinat pada jalur 4 adalah North (Utara, 0311.569) dan East (Timur, 99.99.038).
Jenis tengkawang yang ditemukan pada jalur 4 sebanyak 2 jenis. Jenis tengkawang yang ditemukan di jalur jelajah 4 di Desa Mensiau Kecamatan Batang Lupar Kabupaten Kapuas Hulu disajikan pada Tabel 5.

Tabel 5. Jenis Tengkawang yang ditemukan pada jalur jelajah 4 di Desa Mensiau Kecamatan Batang Lupar Kabupaten Kapuas Hulu (Tengkawang tree at $4^{\text {th }}$ line of inventory at Mensiau village, Batang Lupar Subdistrict, Kapuas Hulu regency)

\begin{tabular}{lllrr}
\hline No & Nama ilmiah & Nama dagang & Nama lokal & Jumlah \\
\hline 1. & Shorea stenoptera & Meranti kuning & Engkabang tungkul & 167 \\
2. & Shorea beccariana & Meranti merah & Engkabang rambai & 356 \\
\hline & & & Total & 523 \\
\hline
\end{tabular}

\section{Morfologi Vegetatif Tengkawang}

Jenis tengkawang terbanyak yang ditemukan adalah Shorea beccariana Burck, yakni 571 pohon. Deskripsi ciri-ciri morfologi dari masing-masing spesies yang diperoleh langsung dari lapangan yang terdapat pada kawasan Desa Mensiau Kecamatan Batang Lupar Kabupaten Kapuas Hulu diverifikasi dengan buku identifikasi tengkawang. Hasil identifikasi ciri-ciri morfologi dari masing - masing jenis tengkawang yang ditemukan disajikan sebagai berikut:

\section{Shorea stenoptera Burck (Engkabang Tungkul)}

Nama lokal oleh masyarakat adalah Engkabang tukul. Habitus pohon dengan tinggi $20 \mathrm{~m}$, tajuk rapat, cabang-cabang berukuran sedang dan berpencar, menjuntai. Banir besar menyebar dengan tinggi 1,4 m, tebal banir $14 \mathrm{~cm}$. Batang lurus, diameter $13 \mathrm{~cm}$, mempunyai gelang batang, permukaan batang sedikit kasar 
dan sedikit mengelupas, warna batang coklat muda dan mempunyai bercak putih yang sangat banyak, batang mempunyai garis - garis di bagian permukaan batang. Tipe daun tunggal, bentuk helaian daun lonjong, bentuk susunan daun berseling, pertulangan daun tersier jelas, tulang daun sekunder 18 pasang, tangkai daun $2,3 \mathrm{~cm}$, daun penumpu berbentuk seperti segitiga tetapi tumpul, panjang daun penumpu 5 $\mathrm{cm}$, lebar daun penumpu $1,5 \mathrm{~cm}$, panjang pangkal daun sampai ujung daun $31,5 \mathrm{~cm}$, bentuk tangkai daun, tepi daun melengkung, permukaan daun sedikit mengkilat dan halus, warna permukaan daun bagian atas mengkilat dan halus saat diraba, warna permukaan daun di bagian bawah agak kusam, pangkal daun tumpul, dan tangkai daun hampir membengkak seluruhnya. Tumbuh pada tanah aluvial agak basah berpasir pada dataran rendah. Saridan, dkk. (2012) menyatakan ciri morfologi habitus pohon kecil sampai sedang, tinggi hingga $50 \mathrm{~m}$, tajuk mengkerucut sampai lonjong. Percabangan rendah, tersebar memanjang dan seperti menjuntai. Banir tipis. Batang lurus, silinder, diameter hingga $50 \mathrm{~cm}$, warna batang coklat tua, permukaan batang licin dan mengelupas, ada tanda melingkar. Tipe daun tunggal, tangkai daun 2,4-4,4 cm, gundul, daun lonjong atau jorong, pangkal tumpul hingga menjantung, ujung daun sedikit lancip, kaku seperti kulit, halus jika disentuh di kedua permukaannya, sisi atas gundul, 2144 x 8,5-25,5 cm. Tulang daun sekunder sangat jelas, 12-19 pasang, lurus lalu melengkung dekat tepi daun, ramping sampai gemuk, tulang daun tersier terlihat, tegak lurus, tidak ada domatia. Daun tengkawang Shorea stenoptera disajikan pada Gambar 1.
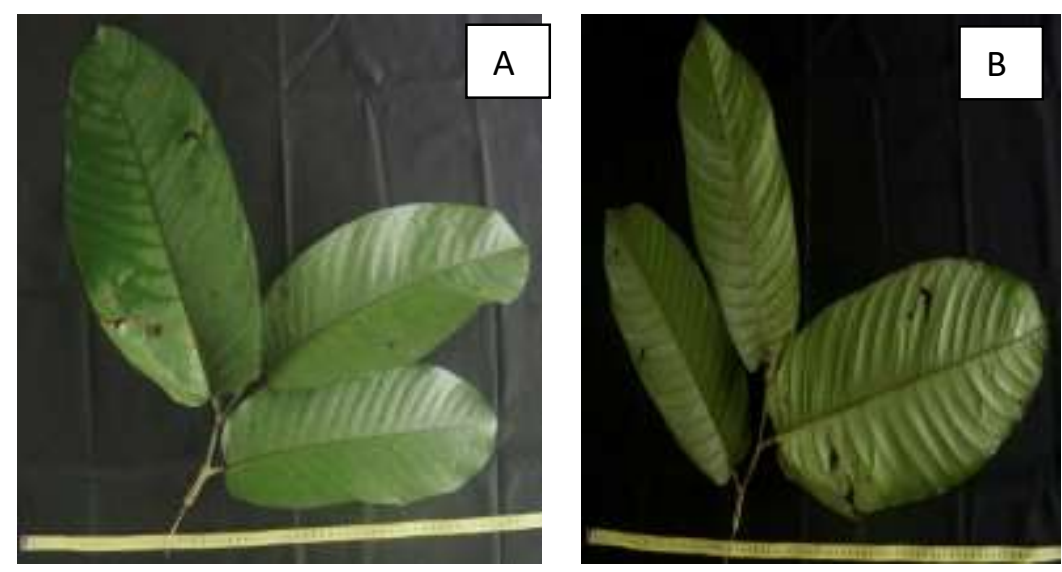

Gambar 1. Daun tengkawang Engkabang Tungkul, Shorea stenoptera Burck (A): Bagian atas, (B) : Bagian belakang (Leaf of Tengkawang Engkabang Tungkul, Shorea stenoptera Burck (A) : upper side, (B) : back side)

2. Shorea macrophylla (de Vriese) P.S. Ashton (Engkabang Biasa)

Nama lokal oleh masyarakat adalah Engkabang biasa. Habitus pohon tinggi
$25 \mathrm{~m}$, tajuk besar dan melebar, dan setengah bulat, cabang besar. Berbanir rendah $1 \mathrm{~m}$, sedikit menyebar, tebal banir $10 \mathrm{~cm}$. Batang lurus berbentuk 
silinder, diameter $40 \mathrm{~cm}$, permukaan batang berwarna kelabu, permukaan batang sedikit kasar saat diraba, memiliki sedikit bercak putih, memiliki warna coklat tua, mempunyai garis seperti pulau, terlihat mengkilat dan licin. Tipe daun tunggal, bentuk helaian lonjong, bentuk susunan daun berseling, pertulangan daun sekunder 13, pertulangan daun tersier sangat jelas terlihat, tangkai daun $3 \mathrm{~cm}$, mempunyai daun penumpu dan tumpul di bagian ujung, panjang daun penumpu 4,2 cm, lebar daun penumpu 1,3 cm, panjang pangkal daun sampai ujung daun $40 \mathrm{~cm}$, mempunyai bulu yang sangat halus, ujung daun meruncing pendek, tepi daun agak melengkung, permukaan daun di bagian atas bawah terlihat mengkilat dan licin, dan tangkai daun kecil, pangkal daun tumpul. Tumbuh di tepi sungai, pada tanah aluvial dan lembab. Jenis tengkawang $S$. macrophylla ditemukan di Dusun Keluin. Daun S. macrophylla disajikan pada Gambar 2.
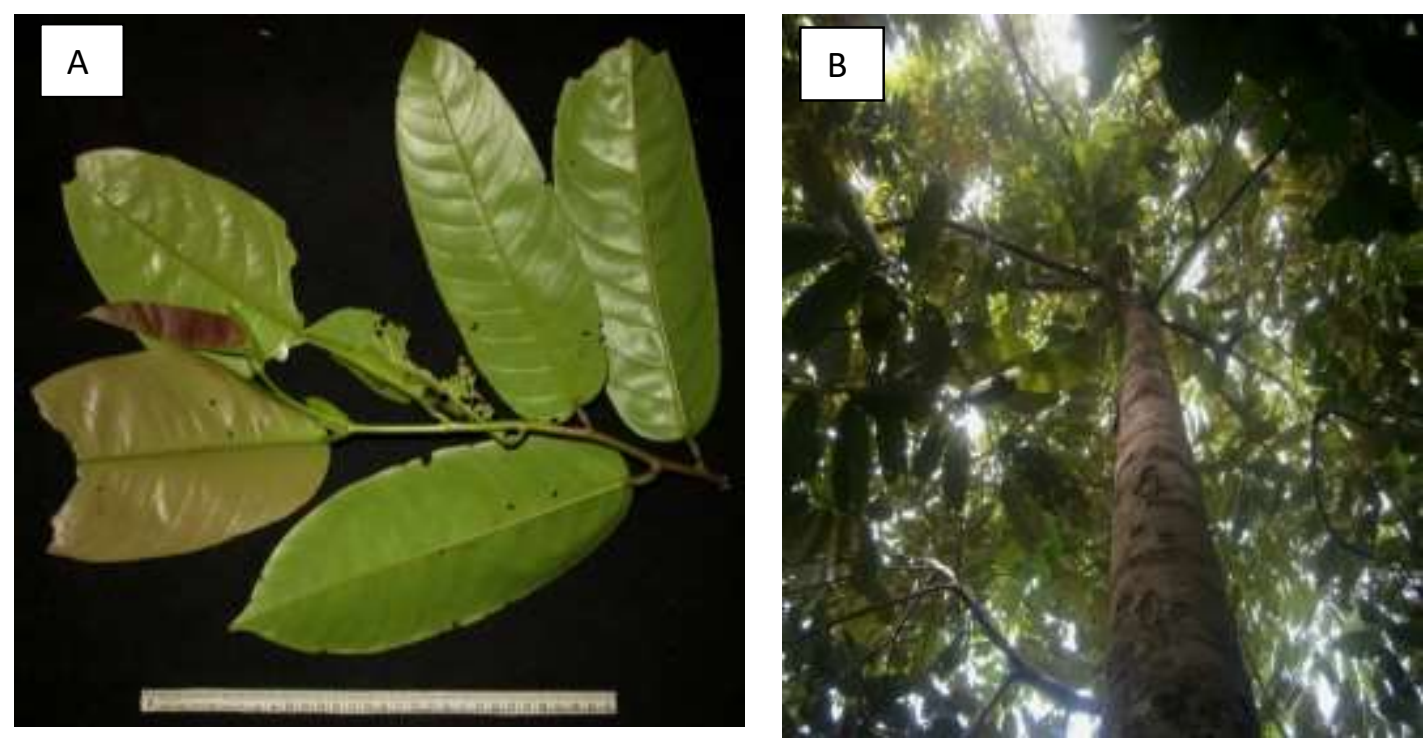

Gambar 2. Tengkawang Engkabang Biasa, Shorea macrophylla (de Vriese) P.S. Ashton, (A): Daun (B): Tajuk (Tengkawang Engkabang Biasa, Shorea macrophylla (de Vriese) P.S. Ashton, (A): leaf, (B): canopy)

\section{Shorea pinanga Scheff} (Engkabang Langai)

Nama lokal Engkabang langai. Habitus pohon tinggi $25 \mathrm{~m}$, tajuk terbuka, ranting menjuntai, cabang merapat. Berbanir rendah $1,2 \mathrm{~m}$, tebal banir $8 \mathrm{~cm}$. Batang lurus, silinder, diameter $20 \mathrm{~cm}$, permukaan batang berwarna kelabu, memiliki bercak putih, bercak hijau, bercak coklat tua, mempunyai bintik bintik di permukaan batang, mempunyai garis seperti pulau, dan permukaan batang sangat kasar saat diraba. Tipe daun tunggal, bentuk helaian daun bulat telur, bentuk susunan daun berseling dan menjarang, pertulangan daun sekunder 14 pasang, pertulangan tersier telihat, tangkai daun $1,5 \mathrm{~cm}$, mempunyai daun penumpu 
dan lancip, panjang daun penumpu $2,2 \mathrm{~cm}$, lebar daun penumpu $0,8 \mathrm{~cm}$, panjang pangal daun sampai ujung $24,4 \mathrm{~cm}$, tangkai daun tidak mempunyai bulu, ujung daun lancip panjang, permukaan daun bagian atas dan bawah licin, halus, mengkilat, tangkai daun kecil, pangkal daun meruncing. Tempat tumbuh tepi sungai, tanah aluvial, lembab, dan ditemukan di Dusun Kelawik.

Menurut Saridan dkk (2012) pohon $S$. pinanga memiliki habitus pohon sedang hingga besar mencapai tinggi 60 $\mathrm{m}$, tajuk terbuka, percabangan menyebar, menaik di pangkalnya dan menjuntai di ujungnya. Banir tebal dan tingginya hingga 1,5 $\mathrm{m}$, menyebar, cekung membulat. Batang lurus silindris, diameter

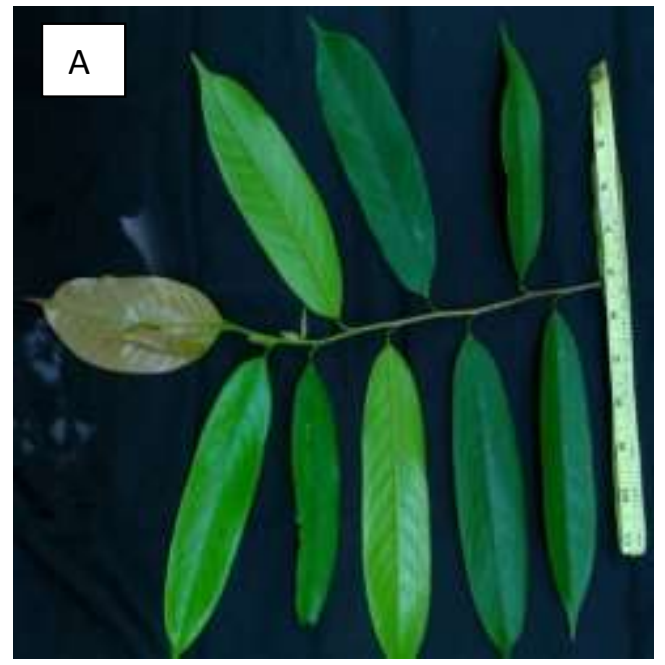

mencapai $130 \mathrm{~cm}$, permukaan Kulit batang licin dan mengelupas besar-besar, warna coklat merah muda pucat, bergelang, berlentisel kecil warna oranye. Tangkai daun 1,1-2,2 cm, gundul atau ada indumentum rapat warna coklat kelabu. Daun 11,5-21 x 4,9-9 cm, kaku seperti kulit, lonjong atau bundar telur menyempit, ujung melancip panjang atau pendek melebar, pangkal membaji, membulat atau sedikit menjantung, tulang daun sekunder 10-16 pasang, meleng kung, tulang tersier jelas dan tegak lurus, tidak ada domatia. Daun penumpu 36-60 x 12-17 mm, menyegi tiga, lancip, merah atau magenta ketika muda, lambat laun menjadi hijau. Pohon S. pinanga disajikan pada Gambar 3.

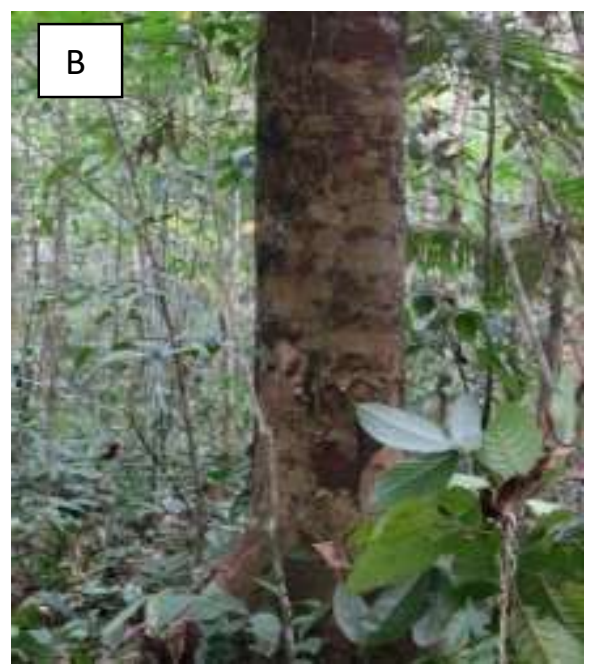

Gambar 3. Tengkawang Engkabang Langai Shorea pinanga Scheff (A) : Daun (B) : Batang (Tengkawang Engkabang Langai Shorea pinanga Scheff (A) : leaf, (B) : stem)

\section{Shorea seminis (de Vriese) Sloot} (Engkabang Trindak)

Ciri - ciri morfologi di lapangan habitus pohon tinggi $32 \mathrm{~m}$, tajuk sedang rapat, percabangan sedikit dan rendah. Berbanir rendah dengan tinggi $1,5 \mathrm{~m}$, tebal banir $4 \mathrm{~cm}$, menyebar. Batang berbentuk silinder, dimeter $24 \mathrm{~cm}$, permukaan kulit batang berwarna coklat tua, kulit batang kasar, permukaan batang pecah - pecah dan sangat kasar sekali saat diraba, bercak kelabu dan mempunyai bercak putih. Tipe daun tunggal, bentuk helaian daun lonjong, bentuk susunan daun berseling, 
pertulangan daun sekunder 19 pasang, pertulangan tersier sangat jelas terlihat, tangkai daun $1,3 \mathrm{~cm}$, mempunyai daun penumpu yang sangat kecil dan berbentuk lonjong, panjang daun penumpu $0,7 \mathrm{~cm}$, lebar daun penumpu $0,4 \mathrm{~cm}$, panjang pangkal daun sampai ujung daun $16,1 \mathrm{~cm}$, ujung daun runcing, permukaan daun bagian atas mengkilat, dan permukaan daun bagian bawah agak kusam, warna daun terlihat sedikit kelabu, tepi daun melengkung pangkal daun jorong, tangkai daun kecil. Tempat tumbuh di tepi sungai, tanah aluvial dan lembab. Pohon tengkawang $S$. seminis ditemukan di kawasan hutan di Dusun Keluin, Dusun Entebuluh, dan Dusun Kelawik. Menurut Saridan dkk (2012) S. seminis habitus pohon sedang tinggi, mencapai $30 \mathrm{~m}$, tajuk rapat berbentuk setengah bulat terbuka, sedang atau besar, percabangan rendah hampir menyebar. Banir membulat, pada pohon yang kurang baik rendah dan kecil, pada bentuk pohon yang baik tinggi banir mencapai $2 \mathrm{~m}$, bentangan 1,5 m. Batang silindris, permukaan kulit batang mengelupas tidak beraturan, licin, memiliki warna coklat kehijauan sampai coklat kehitaman. Tangkai daun 1-1,6 cm, daun lanset atau jorong atau bundar telur, seperti kulit, 9-18 x 2,5-8 cm, ujung melancip panjang, pangkal membaji atau membundar, simetris, tulang sekunder 917 pasang, lurus lalu melengkung dekat tepi atau melengkung sepanjang tulang daun, menonjol tapi memipih, tulang tersier tak tampak atau hampir terlihat, bentuk tangga, Jika ada domatia, letaknya di ketiak pertulangan daun. Daun penumpu Kecil, lonjong, 6-13 x 3-7,5 mm, jorong, tumpul dan cepat luruh,berbulu pendek warna coklat kelabu dan sangat halus, bekas daun penumpu tak mudah terlihat, pendek, hingga $1 \mathrm{~mm}$. Pohon tengkawang $S$. seminis yang ditemukan di Desa Mensiau disajikan pada Gambar 4.
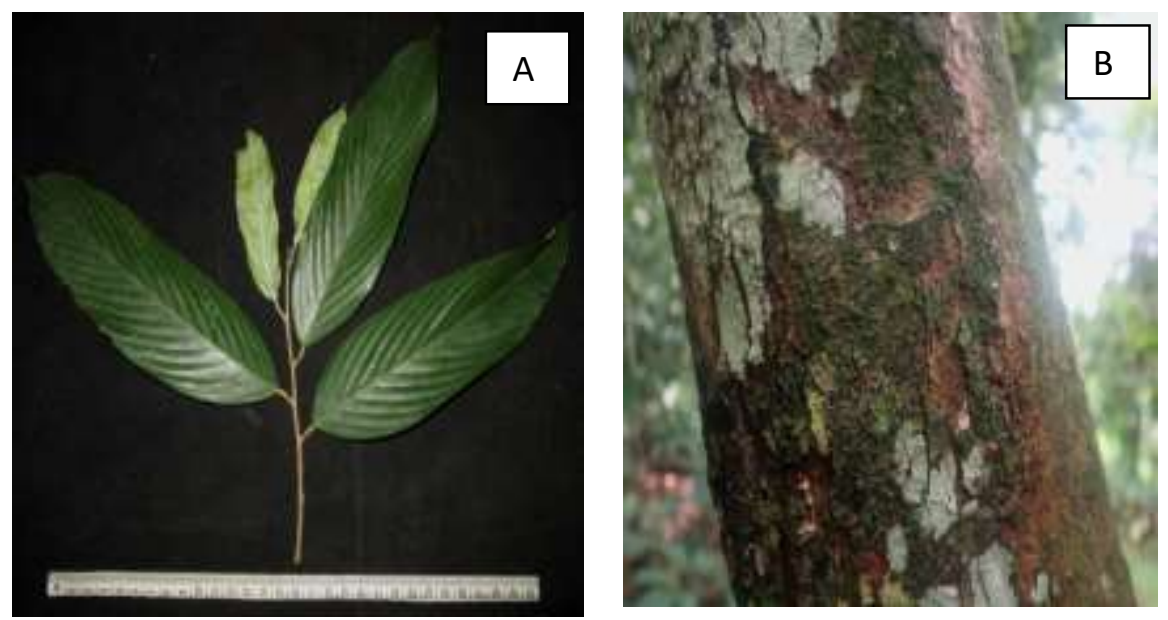

Gambar 4. Tengkawang Engkabang Trindak, Shorea seminis (de Vriese) Sloot (A): Daun (B): Batang (Tengkawang Engkabang Trindak, Shorea seminis (de Vriese) Sloot $(A)$ : leaf, $(B)$ : stem)

\section{Shorea beccariana Burck}

\section{(Engkabang Rambai)}

Ciri - ciri morfologi yang diperoleh

langsung dari lapangan habitus pohon dengan tinggi $50 \mathrm{~m}$, tajuk rapat dan melebar, percabangan banyak serta tinggi. Berbanir rendah dengan tinggi $1,7 \mathrm{~m}$, tebal banir $5 \mathrm{~cm}$, menyebar. 
Batang berbentuk silinder, diameter 27 $\mathrm{m}$, warna permukaan batang coklat muda, memiliki bercak coklat tua, dan bercak putih, permukaan batang licin, mempunyai gelang yang sangat jelas, dan bintik - bintik di batang pohon. Tipe daun tungal, bentuk helaian daun lonjong, bentuk susunan daun berseling, pertulangan daun sekunder 13 pasang, pertulangan daun tersier sedikit terlihat, tangkai daun $1,5 \mathrm{~cm}$, daun penumpu melancip, panjang daun penumpu 1,5 $\mathrm{cm}$, lebar daun penumpu 0,6 $\mathrm{cm}$, panjang pangkal daun sampai ujung daun $19 \mathrm{~cm}$, mempunyai bulu yang sangat jelas dan kasar, ujung daun meruncing, permukaan daun di bagian atas licin dan terlihat mengkilat, sedangkan permukaan daun bagian bawah kasar, tepi daun rata dan melengkung dibagian ujung daun,tangkai daun membengkak, pangkal daun tumpul. Tempat tumbuh,tumbuh pada dataran rendah, tanah podsolik coklat di perbukitan.

Berdasarkan Saridan dkk (2012) ciri morfologi Shorea beccariana meliputi habitus pohon besar, tinggi mencapai $32 \mathrm{~m}$. Banir rendah $1,5 \mathrm{~cm}$. Tajuk kecil, kurang lebih setengah bundar merata, kadang asimetris. Batang bebas cabang tinggi, lurus, silinder, sedikit melancip, kulit permukaan batang berwarna kelabu hingga coklat lembayung berbercak, licin, jelas bergelang, permukaannya licin dengan tanda menggulung berwarna coklat lembayung. Takikan kulit luar tipis, keras, kulit terluar yang kasar (periderm) merah gelap kecoklatan, kulit dalam merah muda atau merah kecoklatan, warna merata tapi pada pohon tua biasanya ada sejumlah lapisan garis merah dan kuning kemerah mudaan. Tangakai daun 1,5-2,7 cm, kadang melutut, ada indumentum pendek yang jarang atau lebat warna kelabu, kelabu coklat atau coklat, daun lonjong atau bundar telur, 8-26 x 2,9-8 cm, seperti kulit, licin jika disentuh di dua permukaannya, pangkal membaji, membundar, atau agak menjantung, ujung melancip pendek, tulang daun sekunder 10- 13, melengkung, tulang daun tersier terlihat jelas, tegak lurus. domatia tidak ada. Daun penumpu 31-35 x 8-9 mm, lekas luruh, menyegitiga, melancip, bekas daun penumpu pendek, kurang lebih lurus agak melengkung ke atas. Pohon tengkawang $S$. beccariana yang ditemukan di Desa Mensiau disajikan pada Gambar 5. 
JURNAL TENGKAWANG (2018)

Vol. 8 (2) : 110 - 121
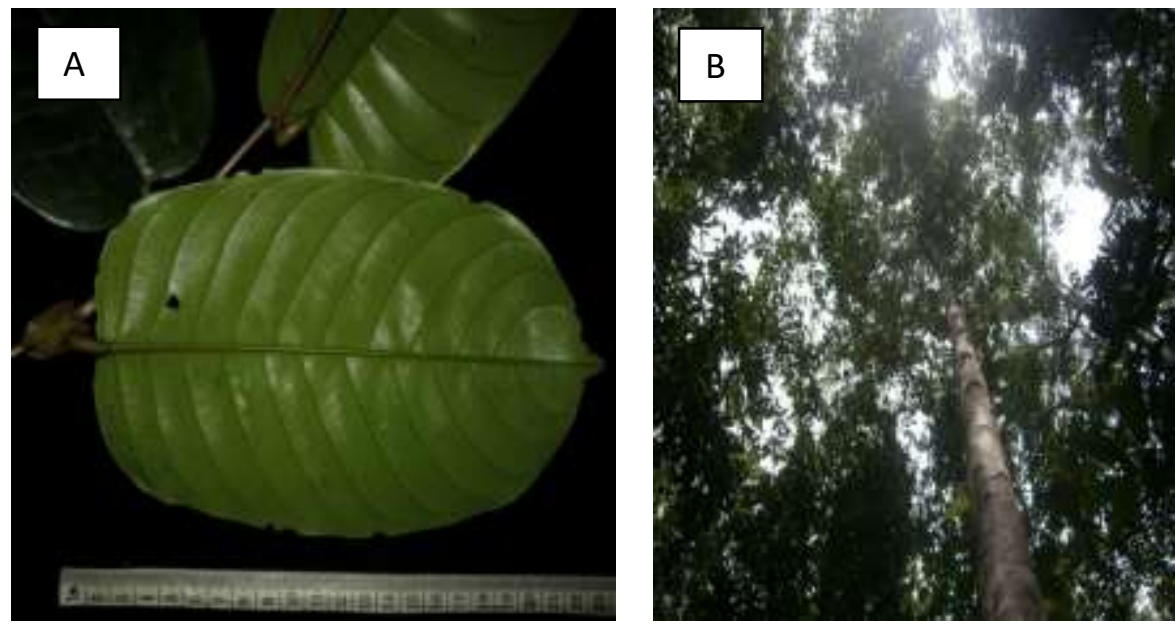

Gambar 5. Tengkawang Engkabang Rambai, Shorea beccariana Burck (A): Daun (B): Tajuk (Tengkawang Engkabang Rambai, Shorea beccariana Burck (A) : leaf, (B) : canopy)

\section{Kesimpulan}

1. Hasil identifikasi ciri-ciri morfologi jenis-jenis tengkawang yang terdapat di Desa Mensiau Kecamatan Batang Lupar Kabupaten Kapuas Hulu ditemukan sebanyak lima jenis pohon tengkawang dengan jumlah 1.689 spesis, yakni: Shorea stenoptera Burck berjumlah 408 pohon, Shorea beccariana Burck berjumlah 571 pohon, Shorea pinanga Scheff berjumlah 370 pohon, Shorea seminis (de Vriese) Sloot berjumlah 186 pohon, dan Shorea macrophylla (de Vriese) P.S. Ashton berjumlah 154 pohon.

2. Keberadaan pohon tengkawang yang paling dominan di Desa Mensiau Kecamatan Batang Lupar Kabupaten Kapuas Hulu adalah Shorea beccariana Burck berjumlah 571 pohon.

3. Jenis pohon tengkawang yang terdapat di semua jalur penelitian adalah Shorea stenoptera Burck berjumlah 408 pohon.

\section{Saran}

Peran serta masyarakat di Desa Mensiau Kecamatan Batang Lupar Kabupaten Kapuas Hulu sangat diperlukan untuk menjaga keberadaan hutan tersebut agar jenis pohon tengkawang dan jenis pohon yang bernilai tinggi tetap terjaga keberadaannya.

\section{DAFTAR PUSTAKA}

Anonim, 1986. Tengkawang. Pusat Penelitian dan Pengembangan Hutan, Badan Penelitian dan Pengembangan Kehutanan, Departemen Kehutanan. Bogor.

Appanah, S, 1998. A Review of Dipterocarps: Taxonomy, Ecology and Silviculture. Center for International Forestry Research, Bogor. Indonesia

Biro Pusat Statistik, 1999. Perdagangan Luar Negeri. Jakarta.

Jafarsidik, Y. dan Oetja, 1982. Pengenalan Jenis Pohon Penghasil Tengkawang. Balai Penelitian Hutan. Bogor.

Rugayah, 2004. Pedoman Pengumpulan Data Keanekaragaman Flora. Bogor Pusat Penelitian Biologi, LIPI. 
JURNAL TENGKAWANG (2018)

Vol. 8 (2) : 110 - 121

Saridan, Amiril dan Ngatiman, 2012.

Eksplorasi jenis-jenis Dipterocap.

Jurnal Balai Besar Penelitian

Dipterocapaceae $6 \quad$ (1):21-32.

Samarinda

Winarni, E. S. Sumadiwangsa dan Dendy Setyawan, 2004. Pengaruh Tempat Tumbuh, Jenis Dan Diameter Batang Terhadap Produktifitas Pohon Penghasil Biji Tengkawang. Jurnal Balai Besar Penelitian

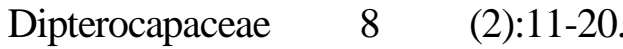
Samarinda 